\title{
7 Traits Associated with Invasiveness in Alien Plants: Where Do we Stand?
}

Petr Pyšek and DAvid M. Richardson

\subsection{History of the Search for Traits and Shifts in Research Focus}

Any organism must be equipped for life in a given environment, otherwise it will die. The fundamental question is how well does an organism need to be "equipped", or what syndrome of traits must it possess to survive and flourish at a given locality. In the current human-mediated biodiversity crisis, where alien species play an important role, we need to know whether some species are inherently better equipped to become invasive when moved to new areas by humans. If so, we can identify such species and consider management options to prevent, or at least reduce the damaging effects of biological invasions.

Despite the importance of chance and timing in the establishment and spread of alien plants (Crawley 1989), invasions are clearly not entirely random events (Crawley et al. 1996). Much of the early work on invasions was directed at collating traits associated with invasiveness (Booth et al. 2003). The question of whether is it possible to determine a set of traits that predispose a species to be invasive has been a central theme since the emergence of invasion ecology as a discrete field of study (Richardson and Pyšek 2006).

Many studies have attempted to profile successful invaders, starting with Herbert Baker's attempt to identify the traits of an "ideal weed" (Baker 1965), an idea now considered simplistic (Perrins et al. 1993). Baker defined as a weed a plant growing "entirely or predominantly in situations markedly disturbed by man (without, of course, being deliberately cultivated plants)". To him, weeds included plants that encroached onto agricultural land (agrestals), and those occurring in waste places (ruderals; Baker 1965). There was no explicit reference to the status of the species as being native or alien. Perhaps it was the two species pairs he used to document different traits of "weedy" 
and "non-weedy" plants (alien and native congeners in the genera Eupatorium and Ageratum) that made followers consider Baker's "ideal weed" to be synonymous with "ideal invader" (i.e., an alien plant spreading from sites of introduction). Nevertheless, Williamson (1993) concluded that there is no consistency of life history and reproductive behavior across all weeds, and the same holds for invading plants (Williamson and Fitter 1996).

Work undertaken in the post-Baker era has shown that identifying traits consistently associated with invasiveness is difficult (Alpert et al. 2000); this resulted in a widespread pessimism in the mid-1990s (Crawley 1987; Roy 1990). However, Rejmánek (1996) showed that such traits are a crucial ingredient for explaining (and therefore predicting) invasions. Rejmánek's paper probably stimulated attempts to find correlates of invasiveness across vascular plants, because this is when comparative studies based on large species sets started to appear. Studies comparing species pairs or a few congeners started to be published some 15 years earlier (Fig. 7.1), possibly because data needed for comparative multispecies studies have only recently become available. Classification of whole floras with respect to alien or native status of their members, with reliable information based on objective criteria, is still far from being standard, even two decades after the SCOPE project on biological invasions (Richardson et al. 2000a; Pyšek et al. 2004a).

After a period of stagnation in late 1990s, the relative contribution of comparative multispecies studies has been increasing recently (Fig. 7.1). This is obviously due to improved data availability, the advent of online databases,

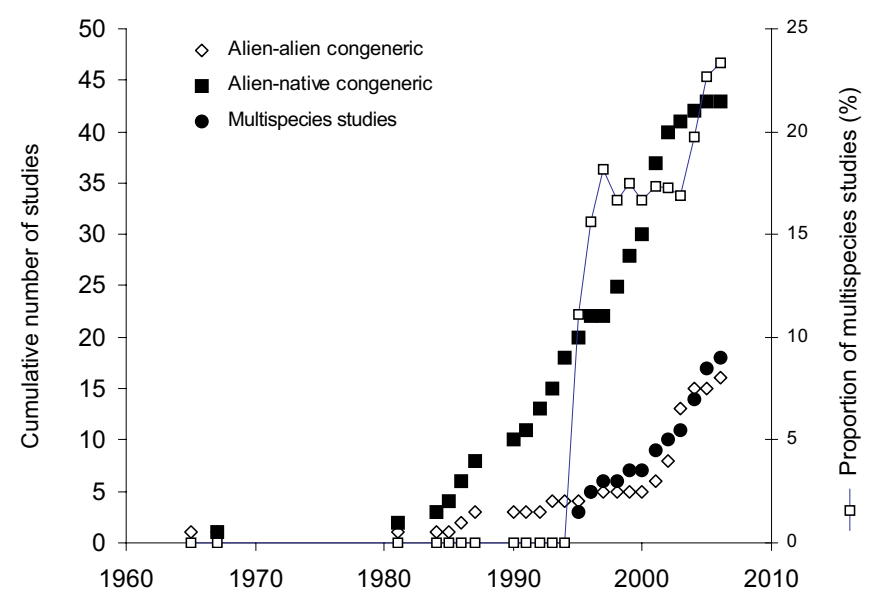

Fig.7.1 Left axis Increase in the cumulative number of studies using different approaches to the analysis of the effect of species traits on invasiveness: comparison of invasive aliens with their native congeners or related genera within a family, comparison of alien congeners with different levels of invasiveness, and comparative analyses of large species sets and whole floras (multispecies studies). Right axis Increase in number of multispecies studies, expressed as a proportion of the cumulative total number of studies 
and better communication among researchers. Powerful computing facilities and statistical techniques also contributed to fairly promising results in some studies, which in turn probably stimulated further work.

Kolar and Lodge (2001) analyzed 16 invasion studies each containing at least 20 plant or animal species, and concluded that sound generalizations have emerged. Gilpin (1990) pointed out that there is pattern in the available data on invasions, and suggested that further efforts in the study of invasions should be self-consciously statistical. If ecologists are unable to predict outcomes of individual cases, then they should focus on uncovering broader, general ecological patterns (Cadotte et al. 2006b).

\subsection{Comparative Analyses of Multispecies Datasets: Every Picture Tells a Story}

\subsubsection{Methodological Approaches: what is Being Compared?}

Can plant invasions be explained and predicted based on the traits of invading species? Has there been real progress, or are we floundering as much as we were 20 years ago? The aim of the present paper is to reassess the potential of studies seeking for plant traits that determine species invasiveness, and to identify such plant characteristics. To achieve this, we need to deal with research approaches first. Just as invasions are notoriously idiosyncratic, so too are the approach methodologies that have been applied to study them.

Multispecies comparative studies need to be classified according to the approach, type of comparison, scale and data character, including measures of occurrence of the species present (Table 7.1). The 18 studies summarized in Table 7.2 use some measure of the occurrence of alien species in the invaded territory, or the presence of aliens and native species as response variables, and explain these by using plant traits. In our analysis, we concentrate on species biological, ecological and physiological traits. We excluded distributional characteristics of alien plants such as the size of native ranges, although such variables are clearly among the best predictors of invasiveness (Rejmánek 1996, 2000). Size of the occupied range is certainly a convenient measure of ecological versatility (Prinzing et al. 2002), but this characteristic results from the interplay of "primary" biological, ecological and physiological traits, and finding a significant link between range size and invasiveness does not tell us much about what traits a plant needs to become a successful invader.

To adopt the correct approach to this issue (column A in Table 7.1), the question being asked needs to be clearly defined (Hamilton et al. 2005). The 


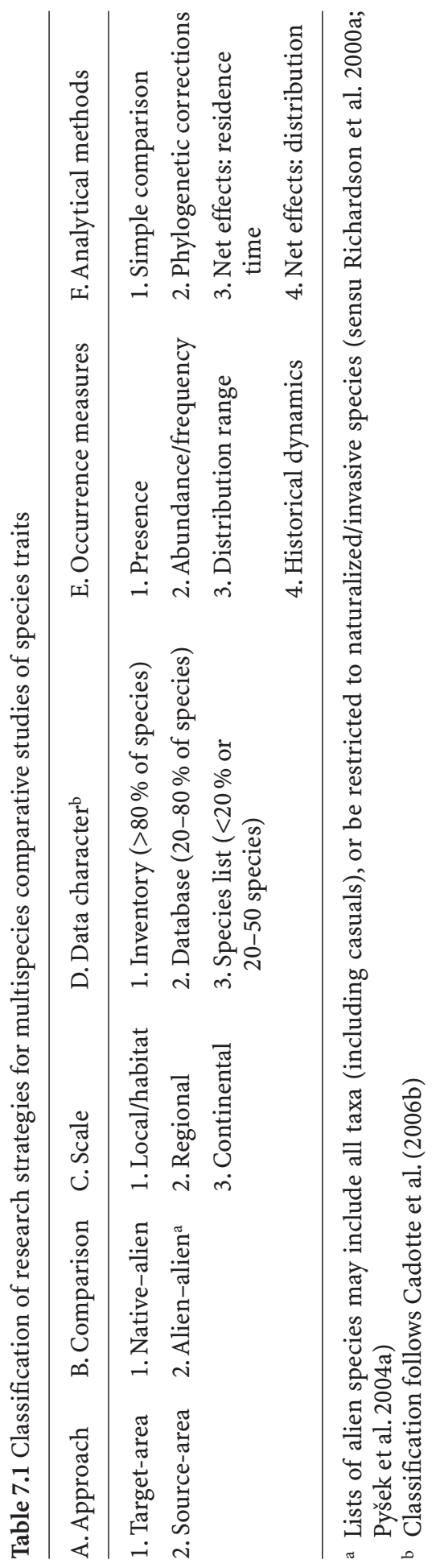


target-area approach focuses on a pool of species that are alien to a region, and attributes the variation in their success to differences in their traits. It asks the question "what traits distinguish successful invaders from those aliens that have not invaded successfully?" (Hamilton et al. 2005). Alternatively, aliens in a target region can be compared with natives of that region. The target-area approach has been more commonly applied than the sourcearea approach (Table 7.2).

The source-area approach (sensu Pyšek et al. 2004b) asks the question "do traits of species that become invasive from a geographic 'source' region differ from those species from the same region that fail to invade?" Such an approach can either identify traits that allow species to pass through early phases (i.e., transport and establishment) of the invasion process (Hamilton et al. 2005), or if factors associated with the chance of being transported are controlled for, provide relatively unbiased estimates of the role of traits associated with naturalization and invasion. The source-area approach is more convenient for identifying net effects of traits because it eliminates or reduces the bias and variation associated with different species origins, and pathways and distance of introduction. In this approach, it is crucial that geographic origin and size of the native range of source-pool species are taken into account, to eliminate these biases as much as possible (Pyšek et al. 2004b); otherwise, the life-history traits of invading species can be confused with environmental circumstances associated with dispersal. Unfortunately, the source area approach has been used in only three studies (Table 7.2). We believe that the main constraint to its wider use is not the lack of information on potential source pools, but rather the lack of knowledge on how these species are performing as invaders elsewhere.

Native-alien comparisons (column B in Table 7.1) explore whether the traits of native species in a target area differ from those of alien species that invaded that area. It asks the question "what traits of the invading species enhance their potential to increase in abundance over native species?" (Hamilton et al.2005). When interpreting the results of alien-native comparisons, one must bear in mind which aliens and which natives are being compared. Not all aliens spread (Richardson et al.2000a), but some natives expand their ranges into human-made habitats, or increase in abundance and/or range following human-induced landscape changes (so-called apophytes, expansive species, see Pyšek et al. 2004a; Alpert et al. 2000). Thompson et al. (1995) compared invasive aliens with expanding natives, and concluded that while invasive species differ significantly from non-invasive species (Thompson 1994), the attributes of invasive aliens are not unique, but most are shared by expanding native species. Comparing these two groups may indicate whether being an alien alone exerts specific effects that are not seen in native expanding taxa (Leishman and Thompson 2005; Hamilton et al. 2005).

Analogically, the alien-alien comparison of two or more invading alien congeners exhibiting different levels of invasiveness asks the question "what 
Table 7.2 Overview of comparative studies of species traits and their effect on plant invasiveness, using large species numbers ${ }^{\mathrm{a}}$

\begin{tabular}{|c|c|c|c|c|}
\hline Author & $\begin{array}{l}\text { Region of invasion/ } \\
\text { source region }\end{array}$ & Research strategy & $\begin{array}{l}\text { Species } \\
\text { number }\end{array}$ & Comparison \\
\hline Thompson et al. (1995) & $\begin{array}{l}\text { England, Scotland, Ire- } \\
\text { land, The Netherlands }\end{array}$ & A1-B1-C2-D3-E1-F1 & 211 alien & $\begin{array}{l}\text { Target/invasive } \\
\text { alien vs. expand- } \\
\text { ing native }\end{array}$ \\
\hline Pyšek et al. (1995) & Czech Republic & $\mathrm{A} 1-\mathrm{B} 12-\mathrm{C} 2-\mathrm{D} 3-\mathrm{E} 12-\mathrm{F} 1$ & 132 alien & $\begin{array}{l}\text { Target/1. natural- } \\
\text { ized neophyte vs. } \\
\text { native; } 2 \text {. within } \\
\text { alien }\end{array}$ \\
\hline Andersen (1995) & Denmark & A1-B12-C2-D3-E1-F1 & $\begin{array}{l}93 \text { alien, } \\
40 \text { native }\end{array}$ & $\begin{array}{l}\text { Target/1. alien } \\
\text { with native; } 2 . \\
\text { alien in ruderal } \\
\text { and seminatural } \\
\text { habitats }\end{array}$ \\
\hline $\begin{array}{l}\text { Crawley et al. } \\
\text { (1996) }\end{array}$ & British Isles & A1-B1-C2-D1-E1-F2 & 1,169 alien & $\begin{array}{l}\text { Target/natural- } \\
\text { ized alien (incl. } \\
\text { archaeophyte) vs. } \\
\text { native }\end{array}$ \\
\hline $\begin{array}{l}\text { Williamson and Fitter } \\
\text { (1996) }\end{array}$ & Great Britain & A1-B1-C2-D1-E1-F1 & $\begin{array}{l}1,777 \\
\text { native } \\
+ \text { alien }\end{array}$ & $\begin{array}{l}\text { Target/invasive } \\
\text { alien vs. native }\end{array}$ \\
\hline Pyšek (1997) & Central Europe & A1-B1-C2-D2-E1-F2 & $\begin{array}{l}\text { 2,223 native, } \\
457 \text { alien }\end{array}$ & $\begin{array}{l}\text { Target/alien with } \\
\text { native }\end{array}$ \\
\hline Pyšek (1997) & $\begin{array}{l}\text { New Zealand: } \\
\text { Auckland }\end{array}$ & A1-B2-C2-D1-E14-F2 & 615 alien & $\begin{array}{l}\text { Target/within } \\
\text { alien }\end{array}$ \\
\hline $\begin{array}{l}\text { Goodwin et al. } \\
\text { (1999) }\end{array}$ & $\begin{array}{l}\text { Canada: New } \\
\text { Brunswick/Europe }\end{array}$ & A2-B2-C2-D3-E1-F2 & $\begin{array}{l}165 \text { species } \\
\text { pairs (invad- } \\
\text { ing+non- } \\
\text { invading) }\end{array}$ & $\begin{array}{l}\text { Source/within } \\
\text { alien }\end{array}$ \\
\hline $\begin{array}{l}\text { Thébaud and Sim- } \\
\text { berloff (2001) }\end{array}$ & $\begin{array}{l}\text { Europe, North America: } \\
\text { California, Carolinas/rec- } \\
\text { iprocal }\end{array}$ & A2-B2-C23-D2-E1-F1 & 651 alien & $\begin{array}{l}\text { Source/within } \\
\text { alien }\end{array}$ \\
\hline
\end{tabular}


Scale Relevant traits compared

Reg. Life strategy, height, lateral spread, flowering time, propagule weight, growth form, clonal growth, seed bank, dispersal mode, canopy structure, habitat preference

Reg. Origin, height, life form, life strategy, dispersal mode, pollen vector, human use, habitat preferences

Reg. Dispersal mode

Reg. Life form, height, seed weight, dispersal mode, seedling relative growth rate, flowering time, pollination mode

Reg. Life form, max. height, spread (height:width), leaf area, leaf shape, leaf longevity, age at 1st flowering, flowering time, seedling relative growth rate, season of seed dispersal, season of germination, pollen vector, fertilization method, breeding system, compatibility

Reg. Clonal growth

Reg. Clonal growth, introduction pathways, habitat preferences

Reg. Growth form, height, flowering period
Results

Aliens more likely clonal, polycarpic perennials with erect leafy stems than are native species, and having transient seed banks

1. aliens more likely than natives to be C- and CRstrategists, dispersed by humans, with preferences for dry, warm and nutrient-rich habitats; 2 . successful aliens in seminatural habitats are tall hemicryptophytes escaped from cultivation; 3. successful aliens in human-made habitat are therophytes or geophytes, introduced spontaneously

Aliens, especially in seminatural habitats, more often with fleshy fruits and dispersed by wind than are natives

Aliens taller, with larger seeds, no or protracted dormancy, flowering earlier or later, with more pronounced r- or K-strategies

Invasive species are tall, taller than wide, more often phanerophytes, have large leaves, are insectpollinated and prefer fertile habitats; natives tend to be more often monoecious

Aliens are more often non-clonal

Clonal aliens are more often introduced deliberately, more likely to increase in numbers and less likely to occur in dry habitats than are non-clonal aliens

Invading species are taller and have longer flowering period than those that do not invade

Species are not taller in their introduced range

Cont. Height 
Table 7.2 (Continued)

\begin{tabular}{|c|c|c|c|c|}
\hline Author & $\begin{array}{l}\text { Region of invasion/ } \\
\text { source region }\end{array}$ & Research strategy & $\begin{array}{l}\text { Species } \\
\text { number }\end{array}$ & Comparison \\
\hline
\end{tabular}

\begin{tabular}{|c|c|c|c|c|}
\hline $\begin{array}{l}\text { Cadotte and Lovett- } \\
\text { Doust (2001) }\end{array}$ & $\begin{array}{l}\text { Canada: SW Ontario } \\
\text { (Essex, Hamilton- } \\
\text { Wenthworth) }\end{array}$ & A1-B1-C2-D1-E1-F1 & $\begin{array}{l}1,330 \text { native, } \\
484 \text { alien }\end{array}$ & $\begin{array}{l}\text { Target/alien with } \\
\text { native }\end{array}$ \\
\hline
\end{tabular}

\section{Prinzing et al. Argentina: Buenos (2002) \\ Aires and Mendoza provinces/Europe}

Pyšek et al. (2003)

Lake and Leishman (2004)

Czech Republic

Australia: Sydney

\begin{abstract}
Sutherland (2004) USA
Hamilton et al. (2005) Eastern Australia (regional: Royal National Park+continental)
\end{abstract}

Lloret et al. (2005) Mediterranean islands

A1-B2-C2-D2-E2-F2

Pyšek and Jarošík (2005)

Czech Republic

Cadotte et al. (2006a) Canada: SW Ontario
A2-B2-C2-D2-E1-F2 197 alien

668 alien

57 alien
A1-B12-C3-D1-E1-F1

A1-B2-C23-D3-E2-F23

152 alien

19,960
native+alien

354 alien

A1-B2-C2-D2-E2-F34

Source/within alien

Target/within alien (neophyte)

Target/alien-alien (invasive vs. noninvasive); alien-native

Target/1. alien with native; 2 . invasive with noninvasive alien (in ruderal habitats)

Target/within alien (introduced in last 200 years)

Target/within naturalized alien

Target/within alien (neophyte)

A1-B2-C2-D1-E2-F23 1,153 alien
Target/within alien

a See Table 7.1 for codes describing the research strategy adopted by individual studies in terms of approach, type of comparison, scale, data character, occurrence measures, and analytical methods used. Only significant results are presented in the last column. Studies are ranked chronologically. Reg., regional, cont., continental 
Scale Relevant traits compared

Reg.

Habitat preferences, life strategy, dispersal vectors, use by humans

Reg. Origin, introduction pathway, growth form, life strategy, time of flowering, dispersal mode, propagule size

Local/ Specific leaf area, leaf texture and hairiness, habitat seed weight, growth form, dispersal mode, vegetative propagation, flowering duration, canopy height

Cont. Vegetative reproduction, breeding system, compatibility system, pollen vector, shade tolerance, growth form, life form, morphology, toxicity

Reg. Specific leaf area, height, seed weight +cont.

Reg. Growth form, vegetative propagation, leaf size, morphology (spinescence, pubescence, succulence), life form, height, breeding system, pollen vector, flowering, fruit type, seed size, dispersal mode

Reg. Introduction pathway, human use, origin, growth form, life strategy, height, flowering time, dispersal mode, propagule size

Reg. Clonal growth, flowering, origin, growth form, breeding system, habitat preferences
Results

Aliens more likely annuals and biennials, hermaphrodites with longer flowering period and with small fruits, less likely to be dispersed by animals; in seminatural habitats, aliens are also more likely trees with many seeds per fruit

Species that invade have r-strategy, prefer warm, dry, sunny and nitrogen-rich habitats, and are more often used by humans

Geographical proximity, early flowering, annual growth form, CSR strategy, and human use contribute to early arrival

Invasive species have higher specific leaf area than do alien non-invasive and native species, and have more hairy leaves in some situations; aliens have softer leaves; invasive species in disturbed sites have smaller seeds and flower longer than do natives; invasives dispersed more by wind and vertebrates, less by ants; aliens more propagated vegetatively than are natives

1. aliens less likely clonal and wetland plants than are natives; 2 . invasive aliens more likely than noninvasives to be monoecious, self-incompatible, perennial and woody

Small seeds correlated with success at both scales, high SLA at continental scale - both with and without phylogenetic correction (all three traits correlated with abundance at both scales, if minimum residence time not controlled for)

Species that reproduce vegetatively, have large leaves, flower in summer and for longer period, or are dispersed by wind and animals have highest abundance; succulent and fleshy fruits favor ruderal and seminatural habitats, respectively

Life strategy, origin and dispersal mode have direct effect, height and growth form interact with minimum residence time; aliens from America and Asia dispersed by water are more frequent

Abundant aliens have longer flowering duration, originated from Europe or Eurasia, and grow in variable soil moistures 
traits enhance the potential of an invasive species to increase in abundance and/or distribution over less-successful alien species?" The two types of comparison are comparatively frequently represented: within the 18 studies summarized in Table 7.2, there are nine native-alien and 13 alien-alien comparisons (some studies use both approaches, e.g., Pyšek et al. 1995; Sutherland 2004; Lake and Leishman 2004).

\subsubsection{Data, Scale and Analysis}

We included only studies based on statistically tested data; the analyzed traits of alien species had to be tested either against those of native species (native-alien approach), or against differing invasion success (alien-alien approach). This is why some papers, often cited regarding traits typical of invaders, are not considered here - they do not compare with "control" datasets (Timmins and Williams 1987), or they are theoretical studies building profiles from examples, but without primary data analysis (e.g., Noble 1989; Roy 1990; Richardson and Cowling 1992).

Multispecies comparative studies also differ in the number of species involved in comparison, whether the species compared are characterized on presence/absence only or some quantitative measure of their occurrence (or some other measure of the extent of invasion) is used, and in the way data are analyzed. Here, we follow the scheme recently suggested by Cadotte et al. (2006b). A complete species inventory (D1 in Table 7.1) results from a concerted, usually long-term effort to record all extant taxa within a large region. A database (D2) covers large representative group of species, $20-80 \%$ of the total number in a region, or a complete inventory from a subregion; it is usually rather a complete list of species that occur in a large, representative habitat or ecosystem. A species list (D3) includes $<20 \%$ of flora in a region, or $50-200$ species in total, and is selected on some a priori criteria, such as a sample from a particular habitat. Available multispecies comparative studies are evenly distributed with respect to the data character, with six studies in D1, D2 and D3 each. Of the 18 studies, 16 are based on more than 100 species, and six on more than 1,000 species (Table 7.2).

The fourth category delimited by Cadotte et al. (2006b), termed species groups, deals with comparisons made on limited numbers of species selected according to some criteria, often congeners or confamilials; these are dealt with below. Congeneric studies have received much focus thus far (Fig. 7.1), given their utility in reducing the influence of phylogenetic effects, and the sense of comparative value (Cadotte et al.2006b). The major reason, nevertheless, is that data on congeners are easier to get - one can collate them in the field in a specifically designed case study. To produce a reliable flora list for a large region (namely, D1 and D2 types in Table 7.1) is much more difficult and not a matter of simple decision; whether it will be possible to analyze such 
alien flora is beyond the researcher's control, as she/he must rely on data that have been collated by others.

The size of the region needs to be appropriate for the questions asked, but larger areas $\left(>100,000 \mathrm{~km}^{2}\right.$, the scale of political regions) are preferable, since species inventories are usually compiled for political regions, are biogeographically arbitrary, and are repeatable (see discussion in Cadotte et al. 2006b). The vast majority of studies (16 in Table 7.2) were conducted at the regional scale, with only a few (Thébaud and Simberloff 2001; Sutherland 2004) addressing the problems at a continental scale. The study by Hamilton et al. (2005) is the only one that compares the effect of studied variables between regional and continental scales. In most studies, cross-species comparisons treating species as independent data points were conducted without explicit consideration of phylogenetic relatedness among species (Cadotte et al.2006b). However, incorporating phylogenetic information can elucidate the extent to which changes in invasiveness may be correlated with changes in other traits through a particular phylogeny (Harvey and Pagel 1991; Cadotte et al. 2006b). Using phylogenetic corrections may, or may not provide different results (Harvey et al. 1995). However, the same results with and without using phylogenetic corrections indicates that throughout the phylogeny of alien species there have been multiple and independent correlated evolutionary divergences between invasion success and the trait examined (as found, e.g., by Hamilton et al. 2005 for seed mass and specific leaf area). The list of studies that used phylogenetic corrections (coded F2 in Table 7.2) clearly indicates that the frequency of its application has been increasing recently, presumably with the gradual improvement in availability of phylogenetic trees for multispecies assemblages. Alternatively, phylogenetic bias can be reduced by comparing invading and non-invading congeners (Goodwin et al. 1999).

The variety of methods, approaches, scales, and measures used in comparative multispecies studies of species invasiveness makes it dangerous to draw generalizations without taking the character of individual studies into account. What can be thus inferred about species traits and their effects on the invasiveness of plant species? Is the message consistent?

\subsubsection{Main Findings of Comparative Multispecies Studies (1995-2005)}

Although the multispecies studies test different hypotheses, simply because the inventories and databases contain different information (Cadotte et al. 2006b), some traits have been tested frequently enough for a pattern to emerge (Table 7.2 and see below).

Growth form (usually separating species into annual, biennial, perennial, shrubs, and trees) and life form (following Raunkiaer's scheme) are the most frequently analyzed traits - obviously because these data are readily available. 
Compared with natives, alien species tend to be longer-lived, i.e., phanerophytes, polycarpic (Thompson et al. 1995; Williamson and Fitter 1996), but also shorter-lived in other studies (Pyšek et al. 1995; Cadotte and LovettDoust 2001). This broader context supports the conclusions of Crawley et al. (1996) that aliens need to "try harder" than native species. They suggested that there are two characteristic groups of aliens that find vacant niches at different ends of niche axes: aliens that are more K-strategists (long-lived, tall, and with big seeds) than native K-strategists (woody and thicket-forming species that are capable of displacing native vegetation), and those that are more $r$ strategists than native r-strategists (small, rapidly maturing, long-flowering species that soon succumb to interspecific competition during secondary succession). Recently, Lloret et al. (2005) provided support for the hypothesis that invasion success may be triggered by functional traits quantitatively different from those occurring in the native flora, in which some life forms may be more saturated than others (Mack 2003).

Within aliens, the role of life form seems to be stage-specific: annuals are promoted in terms of early arrival (Pyšek et al. 2003), but invasiveness seems to be associated with long-lived life forms (Sutherland 2004), and to be habitat-specific: therophytes do better in disturbed, hemicryptophytes in seminatural vegetation (Pyšek et al. 1995). Unlike life histories, Grime's life strategy shows no consistent pattern across studies (Table 7.2).

Not surprisingly, alien species originating on the same continent have tended to arrive earlier in Central Europe (Pyšek et al. 2003), but aliens from more distant regions tend to be more frequent or abundant than those from the same continent. There are only two datasets to support this, but both are very representative and based on large numbers of species from Europe (Pyšek and Jarošík 2005) and North America (Cadotte et al. 2006a).

Plant height is often subjected to testing, for the same reason as growth form. Two studies based on British flora (Williamson and Fitter 1996; Crawley et al. 1996) found aliens to be taller than native species, the latter by using phylogenetic corrections. As far as within-alien comparisons are concerned, although aliens do not seem to be generally taller in their invasive ranges (Thébaud and Simberloff 2001), several studies provided evidence that tallness is associated with invasiveness (Goodwin et al. 1999), and with a higher abundance in some types of habitats (Pyšek et al. 1995), or with increased invasiveness in interaction with other features such as life strategy (Pyšek and Jarošík 2005). We should note, however, that some recent, sophisticated studies that considered height found no relationship between height and invasiveness (Hamilton et al. 2005; Lloret et al. 2005; Cadotte et al. 2006b).

Clonality, along with the ability of vegetative reproduction and good lateral growth, is positively associated with invasiveness, but its effect is contextdependent. The results depend on whether a large set of aliens, including casual species (sensu Richardson et al.2000a), is compared, or the comparison is restricted to naturalized or even invasive species only. In the former case, 
non-clonal species tend to be overrepresented among aliens (Pyšek 1997; Sutherland 2004), but the situation may be reversed in the latter. For more limited data, such as naturalized aliens (Thompson et al. 1995) or smaller species sets in specific habitats (Lake and Leishman 2004), clonal aliens may appear overrepresented compared to clonal natives, become more abundant than non-clonal aliens (Lloret et al. 2005), or increase their abundance at a faster rate (Pyšek 1997).

Only two studies considered specific leaf area (SLA), but both concluded that high SLA promotes invasiveness (Lake and Leishman 2004; Hamilton et al. 2005). This is worth mentioning because congeneric studies strongly indicate that this physiological measure is important (see below, Fig. 7.2). On the contrary, seedling relative growth rate (RGR) was not found significant in two studies; a paper exploring its effect on the distribution of 33 woody species invasive in New Zealand did not find seedlings' RGR nor their survival to be related to invasiveness either (Bellingham et al. 2004).

Breeding system and sex habit were evaluated in two studies using large species sets. For Britain (Williamson and Fitter 1996) and Ontario (Cadotte and Lovett-Doust 2001), it was concluded that alien species are less often monoecious and more likely hermaphroditic than natives. This provides some support, in broader context, for predictions about the importance of a sexual partner being present (Baker 1965). However, Sutherland (2004) found no significant difference for the North American flora (and even indicated that invasive species on this continent are more likely to be monoecious than are non-invasives). In the same vein, there is no evidence that self-compatibility is more common among aliens than among natives (Williamson and Fitter 1996; Sutherland 2004); Sutherland (2004) even reports the opposite - that aliens are more likely to be self-incompatible. Since congeneric studies addressing this issue are rare (Table 7.3), the main support for the importance of being able to reproduce sexually in the new region is from case studies, e.g., Nadel et al. (1992) for Ficus, and Daehler and Strong (1996) for Spartina. In these two genera, sudden events that allowed taxa to reproduce sexually - the formation of an allopolyploid taxon (Spartina), and the arrival of a pollinator (Ficus) - triggered widespread invasions.

Pollen vector has little value in explaining invasion success. Williamson and Fitter (1996) found British aliens to be more likely insect-pollinated than were native species. Using the flora of the same country, Crawley et al. (1996) came to the same result but only for cross-species comparisons, not with phylogenetic corrections applied. None of the four other studies reported significant effects of pollen vector, neither for aliens compared with natives, nor within themselves (Table 7.2). Again, this result seems to be fairly robust because it is strongly supported by congeneric comparisons (Fig. 7.2, Table 7.4).

Timing of flowering is very important, based on 11 studies, seven of which yielded significant results (Tables 7.2, 7.4). Although several studies comparing native and aliens found no significant differences in flowering phenology 
(cf. Thompson et al. 1995; Williamson and Fitter 1996), and Crawley et al. (1996) did so only without applying phylogenetic corrections, other studies clearly show that it is advantageous for an alien to flower for a more extended period, compared to a native (Lake and Leishman 2004 for Australia; Cadotte and Lovett-Doust 2001 for Ontario). The pattern becomes even more distinct in within-alien comparisons: early-flowering species had higher chances to be introduced early to Central Europe (Pyšek et al. 2003), European species invading in Canada flowered longer than their non-invading congeners (Goodwin et al. 1999), and alien species on Mediterranean islands that flower in summer and over longer periods are more abundant (Lloret et al. 2005). Aliens with longer flowering periods are also more abundant in Ontario (Cadotte et al. 2006b). Interestingly, the pattern of flowering found for the British flora by Crawley et al. (1996) - aliens flower earlier or later than natives - supports the "aliens try harder" concept suggested by these authors (see above).

When propagule size was compared for a number of native and alien species, its effect was found to be non-significant (Thompson et al. 1995; Williamson and Fitter 1996), or the results were ambiguous - seeds of aliens were reported to be bigger (Crawley et al. 1996) or very small (Cadotte and Lovett-Doust 2001), or the probability of aliens having seeds smaller than those of natives was associated with disturbed habitats (Lake and Leishman 2004). Most within-alien studies exploring the correlation between seed size and invasion success also yielded non-significant results (Pyšek et al. 2003; Pyšek and Jarošík 2005; Lloret et al. 2005; Cadotte et al. 2006b), the only exception being for Eastern Australia, where small seeds were found to be associated with invasion success at both regional and continental scales (Hamilton et al. 2005). These mostly ambiguous results (as in studies on congeners, Table 7.4) may be partly explained by there being two contrasting groups of aliens - short-lived herbs and woody species, having on average small and large seeds, respectively - each of them successful in different environments. Another reason may be that having both small and large seeds brings about potential pros and cons for an alien plant. Small seeds are correlated with increased seed output (Henery and Westoby 2001), are easily dispersed by wind, and persist longer in soil than do large seeds (Thompson et al. 1993). Large seeds are better for establishment (Harper 1977), and more attractive to vertebrate dispersers (Richardson et al. 2000b). It is, nevertheless, encouraging that Hamilton et al. (2005) in their excellent study, considering phylogenies, net effects and different scales, found small seeds to be significantly correlated with invasion success.

Studies addressing the effect of dispersal mode and efficiency did not arrive at consistent conclusions (Table 7.2). Aliens were reported to be more likely dispersed by humans than were native species (Pyšek et al. 1995; Crawley et al. 1996), and less likely by water, wind (Crawley et al. 1996) and animals (Cadote and Lovett-Doust 2001). These results emerged from analyses of large 
floras, but datasets based on fewer species indicated the opposite - both Andersen (1995) and Lake and Leishman (2004) found aliens to be more often dispersed by wind and vertebrates, or having more fleshy fruits, which indirectly implies the latter. To relate dispersal syndrome to invasion success within aliens is even more difficult - the few available studies highlighted wind, animals (Lloret et al. 2005), and water (Pyšek and Jarošík 2005) as dispersal vectors leading to higher abundance, whereas other studies did not find significant results (Pyšek et al. 1995, 2003; Prinzing et al. 2002). Comparative multispecies studies are constrained by plants being effectively dispersed by many vectors, each of them most efficient under specific circumstances.

Results of comparative large-scale studies on habitat preferences are not easy to interpret, as they reflect variation in habitats present in target areas and the variety of approaches used. Affinity for dry habitats seems to be a feature typical of alien species (Thompson et al. 1995; Prinzing et al. 2002; Sutherland 2004). Surprisingly, only two studies (Williamson and Fitter 1996; Prinzing et al. 2002) out of seven indicated affinity of aliens to fertile soils.

\subsubsection{Biases to Bear in Mind: Residence Time, Scale and Stage}

There are biases that need to be considered when interpreting the results of comparative multispecies studies. Analyses of several pools of alien species have shown that the more time alien species have spent in their introduced ranges, the more likely they are to have become widespread (Pyšek and Jarošík 2005; Cadotte et al. 2006b). To take this into account when exploring net effects of traits requires knowledge of introduction dates, and such data are notoriously hard to obtain for whole floras (Kolar and Lodge 2001; but see Pyšek et al. 2003; Hamilton et al. 2005). Real residence time can be reliably inferred from the date of first reporting (Pyšek and Jarošík 2005; Hamilton et al. 2005). The potential confounding effect of residence time can be demonstrated by the use by humans, which promotes invasiveness in terms of probability of arrival to the new region (Pyšek et al. 2003), and abundance (Pyšek et al. 1995; Prinzing et al.2002). However, this effect may be mediated through the residence time - plants introduced for utility reasons arrived significantly earlier in the Czech Republic than those planted as ornamentals, and accidental introductions were the latest (Pyšek et al. 2003). If minimum residence time is included into the model, the effect of human use becomes non-significant (Pyšek and Jarošík 2005; Hamilton et al. 2005).

The scale of study may represent another potential bias. Studies at a single spatial scale are unlikely to discern the drivers of invasion patterns (Collingham et al. 2000; Lloret et al. 2004; Pyšek and Hulme 2005), and the effect of a given trait may differ at various scales (Hamilton et al. 2005; Lloret et al. 2005). 
When interpreting multispecies studies, one must be aware of the type of comparison and approaches used by the primary researchers. For example, if aliens are compared with natives, then large seeds were identified as typical of aliens (Crawley et al. 1996), but if the analysis is made within aliens, then another study indicated small seeds as promoting invasion success (Hamilton et al.2005). Similarly, Prinzing et al. (2002) did not find dispersal by wind and vertebrates important for species that reached Argentina from the European source pool, while Lake and Leishman (2004) did find this important for the invasion success of aliens in different habitats. Dispersal by wind and animals may not play a role in the chance of a species to overcome major oceanic barriers, where humans are the main vector, while more natural dispersal agents become important for spread in the new territory (Rejmánek et al. 2005). These seeming contradictions also indicate that the effects of individual traits depend on the stage of the invasion process. Social and economic factors are crucial at the introduction stage, biogeographical and ecological factors at the stage of naturalization, and ecological and evolutionary principles are crucial mediators of invasiveness (Perrings et al. 2005).

\subsubsection{Message from Comparative Multispecies Studies}

Cadotte et al. (2006b) generalized that the success of plant invaders was related to a short life cycle, dispersal syndrome, large native range size, non-random taxonomic patterns, presence of clonal organs, occupation of disturbed habitats, and early time since introduction. In this review, we do not deal with range sizes nor habitat affinities, and the effect of introduction time (Rejmánek 2000; Pyšek and Jarošík 2005) and taxonomic patterns are evident (Daehler 1998; Pyšek 1998). Nevertheless, our survey of the 18 studies indicates that the effect of life history is more complicated, and the results reported for dispersal syndrome are far from unambiguous. Presence of clonal organs and ability of vigorous spatial growth certainly promote invasiveness, but these traits are context-specific (Table 7.2). This illustrates that even within the limited number of comparative multispecies studies available to date, different researchers include slightly different datasets (compare Table 7.3 with Table 2 in Cadotte et al.2006b) and interpret them slightly differently.

Our review suggests that comparative multispecies studies provide strong support only for height, vigorous vegetative growth, early and extended flowering, and attractiveness to humans, as traits universally associated with invasiveness in vascular plants (Table 7.4). Studies reporting these findings are not numerous but fairly robust, as they were tested in different regions of the world and are based on different floras. They have potentially useful implications for screening protocols (Daehler et al. 2004).

There are, however, several fundamental limitations of multispecies comparative studies carried out to date. For one, accurate data on many traits of 
interest are not available for most plant species, not even for very widespread and abundant species. Good data are available for plant height, growth form, seed mass and very general "dispersal syndrome", but data on growth rates, palatability, seed production, and many other traits that are crucial for invasion success are incomplete or of highly dubious quality. Nevertheless, as researchers continue to collect life-history and population-level data, the information contained in inventories will continue to improve and contribute to elucidating the role species traits play in plant invasions (Cadotte et al.2006b).

\subsection{Studies of Congeners and Confamilials}

Although some interesting patterns have emerged from the studies reviewed above, it is clear that uncovering a set of traits associated with invasiveness applicable to all vascular plants, and for all of the world's biomes, is totally unrealistic. A trait or set of traits that potentially confers invasiveness to an African Acacia in Australia cannot be expected to do the same for a European grass in North America. Nonetheless, there is value in continuing the search for traits determining invasiveness at a fine taxonomic scale, or for particular life forms or "functional types" (Rejmánek and Richardson 1996).

Much work has thus focused on congeners, confamilials, and otherwise taxonomically and phylogenetically related species (Fig. 7.2). Especially for congeners, such comparisons reduce phylogenetic problems that bedevil interspecific comparisons (Rejmánek and Richardson 1996; Cadotte and Lovett-Doust 2001). This approach involves pairing invasive species with native species or non-invasive congeners - if a consistent difference can be identified between invader and native, then that difference might help to explain invasiveness in some taxa (Daehler 2003).

Following the pioneering studies of Baker (1965) and Harris (1967), congeneric studies of invasiveness started to appear in the 1980s. This interest seems to have been stimulated by the SCOPE program on biological invasions launched in 1982 (Fig. 7.1). Our analysis is based on 46 comparisons of aliens with their native congeners or confamilials, and 18 studies that compare two or more alien congeners differing in their invasiveness (Fig. 7.2). The increase in the number of available studies indicates that alien-native congeneric comparisons have been increasing faster (Fig. 7.1). That there are more studies of this kind simply reflects that there are more such natural experiments available to researchers. Many prominent invaders have native congeners in invaded regions, but the sets of alien congeners invading in the same region, and differing in the degree of invasiveness or status (naturalized vs. casual) are certainly more limited. 


\subsubsection{Assumptions for Congeneric Studies}

In attempting to determine traits of invasive species, ecologists often use species native to the invaded range as control species. Muth and Pigliucci (2006) argue that because many native species themselves are aggressive colonizers, comparisons using this type of control do not necessarily yield relevant information, and suggest that comparing introduced invasives vs. introduced non-invasives is more appropriate. As in the multispecies comparisons discussed above, however, whether native-alien or native-native comparisons are preferred (if we have a choice of such research strategy at all) depends on a concrete situation. If the invader outcompetes the native congener, or they at least coexist in the same type of habitat, then the comparison is relevant and the questions asked are the same as in comparable multispecies studies.

We identified 64 studies comparing one or more pairs of congeners (50 studies), or species from the same family (14 studies). In total, species from 21 families are represented (Fig. 7.2). The criterion for a pair/group of congeneric alien taxa to be included was that they differ in their degree of invasiveness. There was always a notable invasive species, and one or more other alien species that could be considered non-invasive (or at least much less invasive). Therefore, we did not consider studies comparing non-invasive aliens with native species (e.g., Blaney and Kotanen 2001). There is no reason to expect differences in traits explicable by alien status only, i.e., without reference to invasive potential (Crawley et al.1996). It is also important how noninvasive counterparts of invaders are defined. Probably the best approach in terms of eliminating biases was used by Burns (2004). In this study, non-invasive species were those that were cultivated in the same region as invasive congener, but did not escape from cultivation. Ideally, the "invasive" and "noninvasive" species used in a comparison should have been present in a region for approximately the same period of time, and have experienced the same opportunities for sampling a range of potentially invasible sites (e.g., through human-mediated dissemination). Where this was clearly not the case, comparisons were not included in our analysis.

\subsubsection{Searching for Generalities Within Genera}

For each study, we recorded all traits that were subjected to statistical testing in primary papers, and those that were reported to differ significantly between aliens and natives, or invasive and non-invasive aliens. In total, there were 27 traits subjected to testing in at least three studies; these were classified into morphological, physiological, reproductive, and "response" traits the latter comprise the response of species to external factors such as her- 
bivory, burning, or soil conditions (Table 7.4). In terms of structure of the traits considered, alien-native studies focus more on physiology ( $45 \%$ of trait/congeners comparisons) than do within-alien studies; the corresponding value for the latter is $18 \%$, accounted for almost exclusively by measurements of seedling RGR. Comparison of alien congeners deal disproportionately more with reproductive characteristics. In total, the studies analyzed comprised 222 between-congener/confamilial comparisons of individual traits (Table 7.3). The list of analyzed studies covers the majority of published data, and can therefore be regarded as a highly representative sample of current research.

Since we, as in the case of comparative multispecies studies, recorded not only the number of significant results for individual traits, but also their proportion among all tested cases for a given trait, the results summarized in Fig. 7.2 and Table 7.4 provide a reasonably robust assessment of important traits associated with invasiveness in plants.

Some traits associated with invasiveness in multispecies comparative studies also emerge as important in congeneric studies (Table 7.4). Surprisingly, neither approach revealed an unambiguous and positive effect of high biomass on invasiveness, but both did so for plant height. As far as biomass is concerned, a substantial proportion of the 15 studies found its effect non-significant or even opposite, i.e., the native congener had higher biomass than the alien one (Schierenbeck et al. 1994; Smith and Knapp 2001).

Growth rate and allocation to growth appear important; closely associated with this is the capacity for vigorous spatial growth (Fig. 7.2, Table 7.4); this seems to contradict the results of Daehler (2003) who reviewed the performance of co-occurring native and alien species, and did not find higher growth rates, competitive ability nor fecundity to be characteristic of the latter. Rather, the relative performance of invaders and co-occurring natives depended on growing conditions (Daehler 2003). That aliens, compared to natives, or invaders compared to less-invasive taxa, exhibited faster growth is a very robust result in our analysis (Fig. 7.2), and the question arises whether

Table 7.3 Frequencies of pairwise species comparisons classified according to groups of traits and approaches

\begin{tabular}{lccccc}
\hline \multirow{2}{*}{ roup of traits } & \multicolumn{2}{c}{$\begin{array}{l}\text { Number of comparisons } \\
\text { Alien-native }\end{array}$} & Within alien & Total & \multicolumn{2}{c}{$\begin{array}{l}\text { Comparisons (\%) } \\
\text { Alien-native }\end{array}$} & Within alien \\
& & & 36 & 17.6 & 10.9 \\
Morphological & 31 & 5 & 87 & 44.9 & 17.4 \\
Physiological & 79 & 8 & 74 & 27.8 & 54.3 \\
Reproductive & 49 & 25 & 25 & 9.7 & 17.4 \\
Response & 17 & 8 & 222 & & \\
Total & 176 & 46 & & & \\
\hline
\end{tabular}




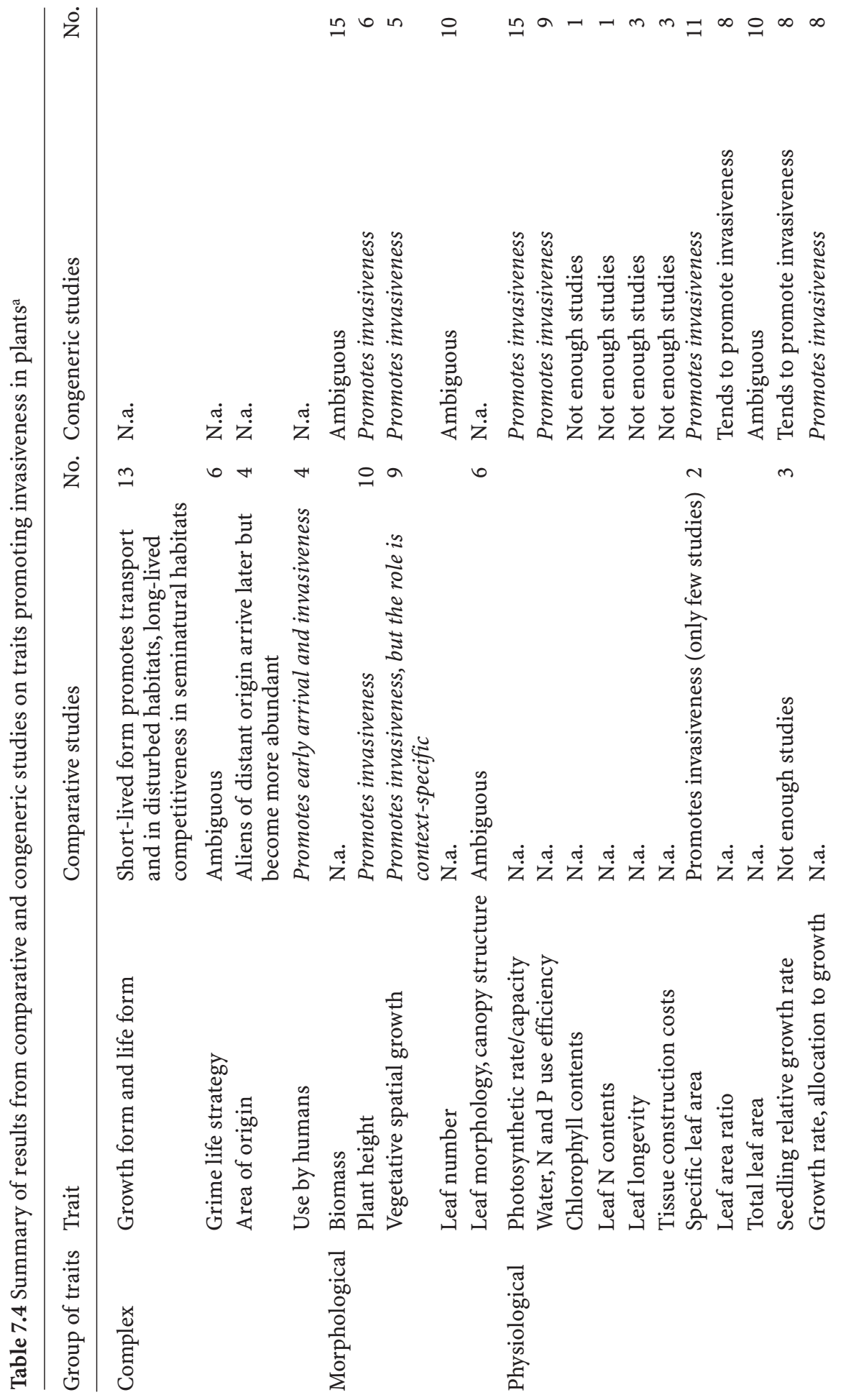




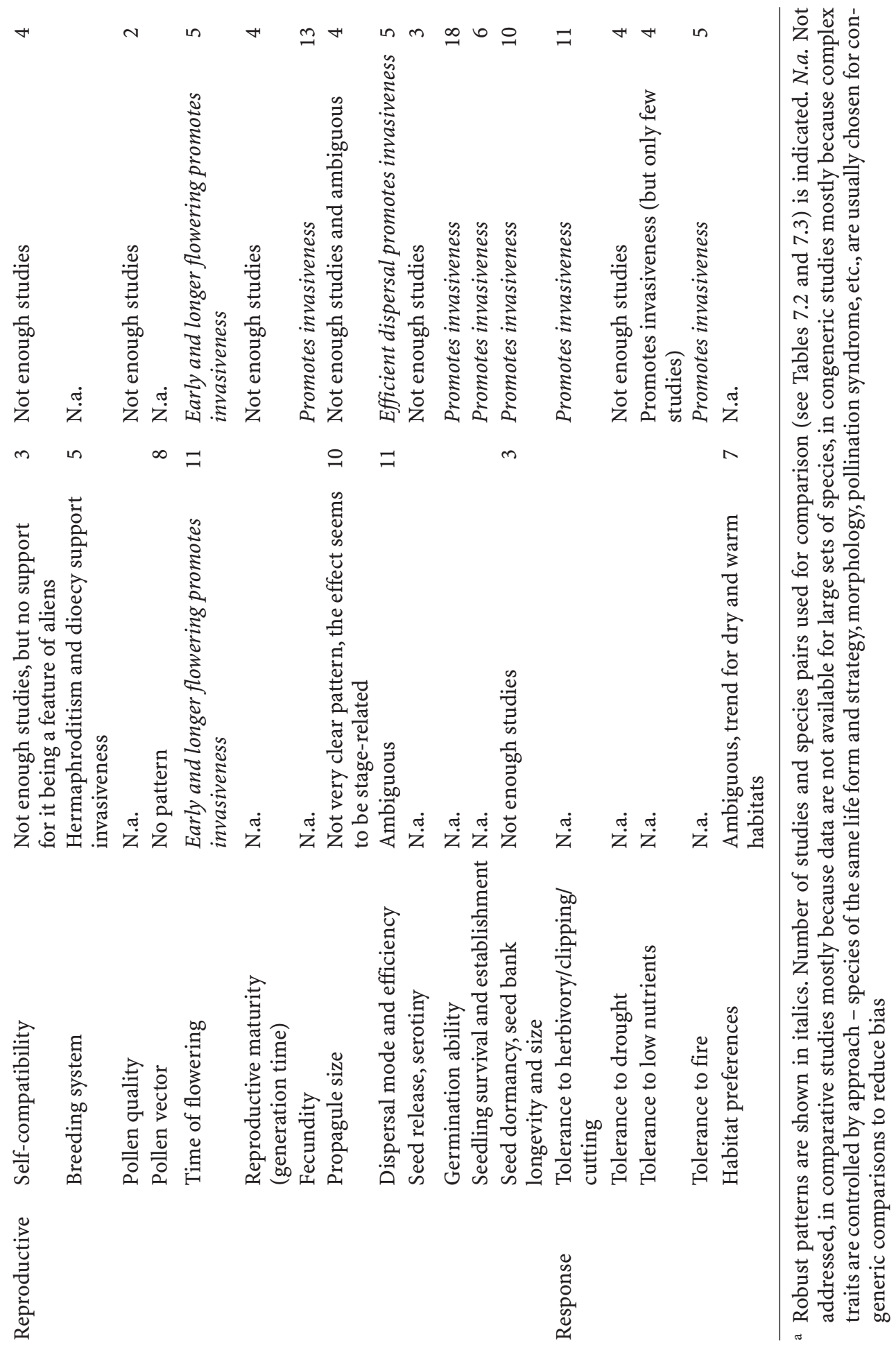




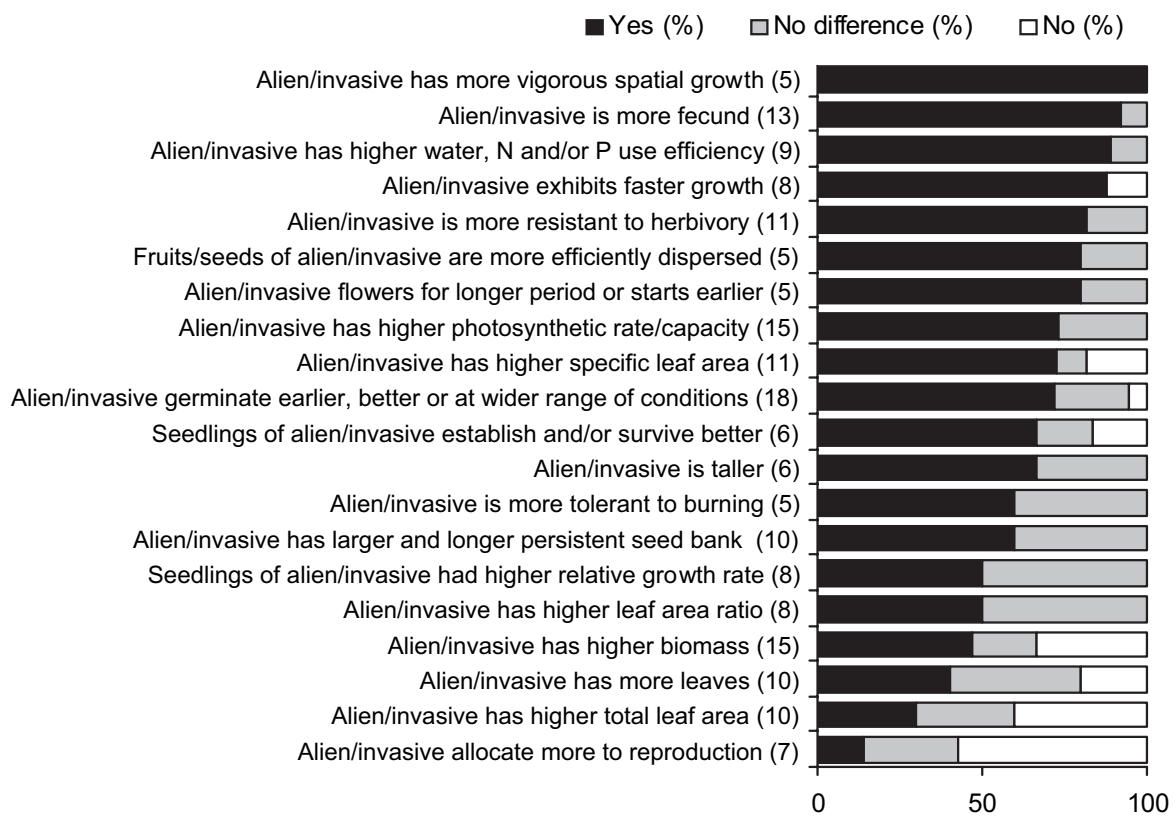

Fig. 7.2 Summary of the results of 59 studies comparing 64 aliens with their native congeners or related taxa, and alien congeners with different degree of invasiveness. Percentages of significant results supporting (yes) or rejecting (no) given statements, or yielding no difference are shown. Traits are listed according to decreasing unambiguousness of results. The number of species pairs on which a given trait was tested is given in parentheses following the statement; only traits tested on at least five species pairs are displayed. The following studies comparing traits of alien and native congeners or closely related taxa within a genus (the latter cases are where family name is given), and of alien congeners differing in the degree of invasiveness were used as dataset: Acer (Kloeppel and Abrams 1995), Ageratum (Baker 1965), Agropyron (Caldwell et al. 1981; Richards 1984; Black et al. 1994), Agrostis (Pammenter et al. 1986), Amsinckia (Pantone et al. 1995), Asteraceae (Smith and Knapp 2001), Atriplex (Mandák 2003), Bidens (Gruberová et al. 2001), Bromus (Kolb and Alpert 2003), Carpobrotus (Vilà and D'Antonio 1998a, b), Celastrus, Parthenocissus, Polygonum (Van Clef and Stiles 2001), Centaurea (Gerlach and Rice 2003), Centaurea, Crepis (Muth and Pigliucci 2006), Cortaderia (Lambrinos 2001, 2002), Crataegus (Sallabanks 1993), Cyatheaceae (Durand and Goldstein 2001), Echium (Forcella et al. 1986), Eucalyptus (Radho-Toly et al. 2001), Eupatorium (Baker 1965), Fabaceae (Smith and Knapp 2001), Hakea (Richardson et al. 1987), Impatiens (Perrins et al. 1993), Lonicera (Sasek and Strain 1991; Schierenbeck and Marshall 1993; Schierenbeck et al. 1994; Schweitzer and Larson 1999; Larson 2000), Mikania (Deng et al. 2004), Oenothera (Mihulka et al. 2003), Oleaceae (Morris et al. 2002), Pinus (Rejmánek and Richardson 1996; Grotkopp et al.2002), Plantago (Matsuo 1999), Poaceae (Harris 1967; Baruch et al. 1985; Pyke 1986, 1987; Bilbao and Medina 1990; Williams and Black 1994; Baruch and Goméz 1996; Holmes and Rice 1996; Baruch and Bilbao 1999; Goergen and Daehler 2001a, b, 2002; Smith and Knapp 2001), Proteaceae (Honig et al. 1992), Reynoutria (Pyšek et al. 2003a; Bímová et al. 2003), Rubus (McDowell 2002; Lambrecht-McDowell and Radosevich 2005), Senecio (Radford and Cousens 2000, Sans et al. 2004), Spartina (Callaway and Josselyn 1992; Anttila et al. 1998), Tradescantia, Commelina, Murdannia (Burns 2004). Citation details can be found at www.ibot.cas.cz/ personal/pysek 
the seemingly contradicting conclusions of Daehler's review could be due to the fact that his review was not confined to congeners. In our analysis, phylogenetic bias is reduced.

In agreement with Daehler (2003), congeneric studies suggest that leaf area is important, although this was manifested as total leaf area in Daehler's dataset (which gave ambiguous results in ours), and as specific leaf area (SLA) in 11 studies in our review (Fig. 7.2). As SLA is positively associated with invasiveness in multispecies comparative studies as well (see above), it seems to be one of most robust indicators/predictors of invasiveness. Invasions are generally associated with disturbed habitats, and high SLA is typical of rapidly colonizing species. High SLA is correlated with short leaf retention and fast growth rate; this is associated with avoidance of investing biomass into longlasting structures, which is, in turn, a critical precondition of success in disturbed habitats where fast growth is paramount (Grotkopp et al. 2002). Of other physiological traits, photosynthetic rate/capacity and water and/or resource use efficiency promote invasiveness, and this pattern is very robust and supported in 15 and nine studies, respectively.

The results of $80 \%$ of studies that address flowering phenology accord with conclusions from multispecies comparative studies; early flowering and extended flowering period, compared to natives/non-invasives, provide invaders with an advantage. Reproductive traits in general appear important determinants of invasiveness, and these traits are identified by congeneric studies much more reliably than by multispecies comparisons, because sufficiently accurate data are mostly not available for large numbers of species. High fecundity and efficient dispersal of seeds promote invasiveness (Fig. 7.2, Table 7.4). Many studies compared features associated with seed germination, dormancy, and seed bank longevity (Fig. 7.2), and together they clearly indicate that easy germination, and long-term seed banks that allow species to extend germination over time and to wait for preferred conditions increase invasiveness.

\subsection{Combining Approaches: Pooling the Evidence}

From the above, it follows that each of the two main approaches discussed has its own strengths and weaknesses. It is symptomatic that the best progress to date toward a general theory of plant invasiveness has been achieved by pooling evidence from both approaches. Genera with enough invasive and non-invasive taxa to enable rigorous statistical analysis, and for which detailed autecological information is available are ideally suited for extracting robust generalizations. The genus Pinus provides the best example known to date. 
Rejmánek and Richardson (1996) were able to explain invasiveness in Pinus species using only three traits (seed mass, length of juvenile period, and interval between good seed crops). They defined a discriminant function that successfully separated invasive and non-invasive species. This framework was expanded, by adding considerations relating to dispersal by vertebrates and characteristics of fruits, and successfully applied to predict invasiveness in other gymnosperms and woody angiosperms (Rejmánek and Richardson 1996; Richardson and Rejmánek 2004).

Rejmánek combined the results from congeneric studies on pines with robust patterns emerging from multispecies comparative studies to formulate his "Theory of seed plant invasiveness", the most ambitious attempt to create a unified scheme (Rejmánek 1996, 2000; Rejmánek et al. 2005). This theory posits that a low nuclear amount of DNA, as a result of selection for short generation time, membership to alien genera, and primary latitudinal range are major factors contributing to the invasiveness of seed plants. Large geographical range is often among the best predictors of invasion success (Rejmánek 1996; Goodwin et al. 1999). Widespread species are more likely to be adapted to a wider range of conditions, and have better chances to be dispersed because they occur in more locations (Booth et al. 2003). Although there are exceptions to this general rule reported for individual species (Richardson and Bond 1991), the same traits that allow a species to be widespread in the native range seem to be also favorable for a successful invasion (Booth et al. 2003). An additional study identified RGR as the most important predictor of invasiveness in disturbed habitats, and related invasiveness to physiological measures (Grotkopp et al. 2002).

\subsection{Conclusions: Where Do we Stand?}

The two main approaches to the role of plant traits in determining invasiveness (Table 7.4) provide complementary answers. The congeneric studies identified a higher number of important traits, because they are better focused and more detailed. Some of the traits simply cannot be addressed by multispecies studies, because this approach is too "coarse-grained". Methodologically, there is another difference between the two approaches. Congeneric/confamilial comparisons, by involving an invasive or at least naturalized alien, address later stages of invasion, while analyses of whole floras are in some cases biased by including casual species. Since different traits potentially influence different stages of invasion (Kolar and Lodge 2001; Pyšek et al. 2003; Perrings et al. 2005), this introduces a bias into multispecies comparisons that does not influence congeneric studies.

On the other hand, conclusions yielded by comparisons of whole floras are fairly robust, and often generally valid for all vascular plants. Detailed con- 
generic studies are sometimes difficult to compare directly because of the variety of methods used, these being specific and suited to a given species, region and the investigator's research priorities.

Cadotte et al. (2006b) recently reminded us of John Harper's contention that historically the field of plant ecology has been dominated by two major themes, i.e., description of vegetation, dealing with species assemblages and their classification, and autecological single-species descriptions (Harper 1977). Seeking traits associated with invasiveness has followed a similar twopronged approach, with multispecies studies being somewhat analogous to vegetation description, and research on congeners comparable to autecological studies. As for plant ecology in general, both approaches yield unique and mutually enriching results.

When looking at the effect of traits on invasiveness, we must remember that different species were introduced at different times and are at different stages of naturalization/invasion. Studies that explicitly attempt to filter out such effects and other biases are extremely useful for revealing inherent traitrelated determinants of invasibility. The role of plant traits in the invasion process is to a very large extent stage- and habitat-specific. Traits that confer an advantage at a given stage of the process, and in a particular habitat may be neutral or even detrimental at another phase and/or for a different habitat.

Most importantly, however, many traits have been tested repeatedly and often enough to allow us to draw fairly robust conclusions regarding their role. This review clearly indicates that successful invaders possess some traits that unsuccessful invaders do not have. Traits do matter! Unfortunately, crucial information is lacking for many species, and the challenge for the invasion-ecology community is to collate such information and to make it widely available.

Acknowledgments. We thank Mark Cadotte and Brad Murray for providing us with their unpublished papers, and Ivan Ostrý and Zuzana Sixtová for logistic support. P.P. was supported by the European Union FP 6 integrated project ALARM (GOCE-CT-2003506675) and by the specific targeted research project DAISIE (SSPI-CT-2003-511202), grant no. 206/05/0323 from the Grant Agency of the Czech Republic, and by institutional long-term research plans no. AV0Z60050516 from the Academy of Sciences of the Czech Republic, and no. 0021620828 from the Ministry of Education of the Czech Republic. D.M.R. acknowledges support from the DST-NRF Centre of Excellence for Invasion Biology. 


\section{References}

Alpert P, Bone E, Holzapfel C (2000) Invasiveness, invasibility and the role of environmental stress in the spread of non-native plants. Perspect Plant Ecol Evol Syst 3:52-66 Andersen UV (1995) Comparison of dispersal strategies of alien and native species in the Danish flora. In: Pyšek P, Prach K, Rejmánek M, Wade M (eds) Plant invasions: general aspects and special problems. SPB Academic, Amsterdam, pp 61-70

Baker HG (1965) Characteristics and modes of origin of weeds. In: Baker HG, Stebbins GL (eds) The genetics of colonizing species. Academic Press, New York, pp 147-172

Bellingham PJ, Duncan RP, Lee GW, Buxton RP (2004) Seedling growth rate and survival do not predict invasiveness in naturalized woody plants in New Zealand. Oikos 106:308-316

Blaney CS, Kotanen PM (2001) Effects of fungal pathogens on seeds of native and exotic plants: a test using congeneric pairs. J Appl Ecol 38:1104-1113

Booth BD, Murphy SD, Swanton CJ (2003) Weed ecology in natural and agricultural systems. CABI, Wallingford

Burns JH (2004) A comparison of invasive and non-invasive dayflowers (Commelinaceae) across experimental nutrient and water gradients. Diversity Distrib 10:387397

Cadotte MW, Lovett-Doust J (2001) Ecological and taxonomic differences between native and introduced plants of southwestern Ontario. Ecoscience 8:230-238

Cadotte MW, Murray BR, Lovett-Doust J (2006a) Evolutionary and ecological influences of plant invader success in the flora of Ontario. Ecoscience 13:388-395

Cadotte MW, Murray BR, Lovett-Doust J (2006b) Ecological patterns and biological invasions: using regional species inventories in macroecology. Biol Invasions 8:809-821

Collingham YC, Wadsworth RA, Willis SG, Huntley B, Hulme PE (2000) Predicting the spatial distribution of alien riparian species: issues of spatial scale and extent. J Appl Ecol suppl 1 37:13-27

Crawley MJ (1987) What makes a community invasible? In: Gray AJ, Crawley MJ, Edwards PJ (eds) Colonization, succession and stability. Blackwell, Oxford, pp 429453

Crawley MJ (1989) Chance and timing in biological invasions. In: Drake JA, Mooney HA, di Castri F, Groves RH, Kruger FJ, Rejmanek M, Williamson M (eds) Biological invasions: a global perspective. Wiley, Chichester, pp 407-424

Crawley MJ, Harvey PH, Purvis A (1996) Comparative ecology of the native and alien floras of the British Isles. Biol Trans R Soc B 351:1251-1259

Daehler CC (1998) The taxonomic distribution of invasive angiosperm plants: ecological insights and comparison to agricultural weeds. Biol Conserv 84:167-180

Daehler CC (2003) Performance comparisons of co-occurring native and alien invasive plants: implications for conservation and restoration. Annu Rev Ecol Syst 34:183-211

Daehler CC, Strong DR (1996) Status, prediction and prevention of introduced cordgrass Spartina spp. invasions in Pacific estuaries, USA. Biol Conserv 78:51-58

Daehler CC, Denslow JS, Ansari S, Kuo H-C (2004) A risk assessment system for screening out invasive pest plants from Hawai'i and other Pacific Islands. Conserv Biol 18:360-368

Dreyer GD, Baird LM, Fickler C (1987) Celastrus scandens and Celastrus orbiculatus comparisons of reproductive potential between a native and an introduced woody vine. Bull Torrey Bot Club 114:260-264

Gerlach JD, Rice KJ (2003) Testing life history correlates of invasiveness using congeneric plant species. Ecol Appl 13:167-179

Gilpin M (1990) Ecological prediction. Science 248:88-89 
Goodwin BJ, McAllister AJ, Fahrig L (1999) Predicting invasiveness of plant species based on biological information. Conserv Biol 13:422-426

Grotkopp E, Rejmánek M, Rost TL (2002) Towards a casual explanation of plant invasiveness: seedling growth and life history strategies of 29 pine (Pinus) species. Am Nat 159:396-419

Hamilton MA, Murray BR, Cadotte MW, Hose GC, Baker AC, Harris CJ, Licari D (2005) Life-history correlates of plant invasiveness at regional and continental scales. Ecol Lett 8:1066-1074

Harper JL (1977) Population biology of plants. Academic Press, London

Harris GA (1967) Some competitive relationships between Agropyron spicatum and Bromus tectorum. Ecol Monogr 37:89-111

Harvey PH, Pagel MD (1991) The comparative method in evolutionary biology. Oxford University Press, Oxford

Harvey PH, Read AF, Nee S (1995) Why ecologists need to be phylogenetically challenged? J Ecol 83:535-536

Henery M, Westoby M (2001) Seed mass and seed nutrient contents as predictors of seed output variation between species. Oikos 92:479-490

Kolar CS, Lodge DM (2001) Progress in invasion biology: predicting invaders. Trends Ecol Evol 16:199-204

Lake JC, Leishman MR (2004) Invasion success of exotic plants in natural ecosystems: the role of disturbance, plant attributes and freedom from herbivores. Biol Conserv 117:215-226

Leishman MR, Thomson VP (2005) Experimental evidence for the effects of additional water, nutrients and physical disturbance on invasive plants in low fertility Hawkesbury Sandstone soils, Sydney, Australia. J Ecol 93:38-49

Lloret F, Médail F, Brundu G, Hulme P (2004) Local and regional abundance of exotic plant species on Mediterranean islands: are species traits important? Global Ecol Biogeogr 13:37-45

Lloret F, Médail F, Brundu G, Camarda I, Moragues E, Rita J, Lambdon P, Hulme PE (2005) Species attributes and invasion success by alien plants on Mediterranean islands. J Ecol 93:512-520

Mack RN (2003) Phylogenetic constraint, absent life forms, and preadapted alien plants: a prescription for biological invasions. Int J Plant Sci 164 suppl 3:185-196

Muth NZ, Pigliucci M (2006) Traits of invasives reconsidered: phenotypic comparisons of introduced invasive and introduced noninvasive plant species within two closely related clades. Am J Bot 93:188-196

Nadel H, Frank JH, Knight RJ (1992) Escapees and accomplices: the naturalization of exotic Ficus and their associated faunas in Florida. Florida Entomol 75:30-38

Noble I (1989) Attributes of invaders and the invading process: terrestrial and vascular plants. In: Drake JA, Mooney HA, di Castri F, Groves RH, Kruger FJ, Rejmanek M, Williamson M (eds) Biological invasions: a global perspective. Wiley, Chichester, pp 301-314

Perrings C, Dehnen-Schmutz K, Touza L, Williamson M (2005) How to manage biological invasions under globalization. Trends Ecol Evol 20:212-215

Perrins J, Fitter A, Williamson M (1993) Population biology and rates of invasion of three introduced Impatiens species in the British Isles. J Biogeogr 20:33-44

Prinzing A, Durka W, Klotz S, Brandl R (2002) Which species become aliens? Evol Ecol Res 4:385-405

Pyšek P (1997) Clonality and plant invasions: can a trait make a difference? In: de Kroon $\mathrm{H}$, van Groenendael J (eds) The ecology and evolution of clonal plants. Backhuys, Leiden, pp 405-427 
Pyšek P (1998) Is there a taxonomic pattern to plant invasions? Oikos 82:282-294

Pyšek P (2003) How reliable are data on alien species in Flora Europaea? Flora 198:499507

Pyšek P, Hulme PE (2005) Spatio-temporal dynamics of plant invasions: linking pattern to process. Ecoscience 12:302-315

Pyšek P, Jarošík V (2005) Residence time determines the distribution of alien plants. In: Inderjit (ed) Invasive plants: ecological and agricultural aspects. Birkhäuser, Basel, pp 77-96

Pyšek P, Prach K, Šmilauer P (1995) Relating invasion success to plant traits: an analysis of the Czech alien flora. In: Pyšek P, Prach K, Rejmánek M, Wade M (eds) Plant invasions: general aspects and special problems. SPB Academic, Amsterdam, pp 39-60

Pyšek P, Sádlo J, Mandák B, Jarošík V (2003) Czech alien flora and a historical pattern of its formation: what came first to Central Europe? Oecologia 135:122-130

Pyšek P, Richardson DM, Rejmánek M, Webster G, Williamson M, Kirschner J (2004a) Alien plants in checklists and floras: towards better communication between taxonomists and ecologists. Taxon 53:131-143

Pyšek P, Richardson DM, Williamson M (2004b) Predicting and explaining plant invasions through analysis of source area floras: some critical considerations. Diversity Distrib 10:179-187

Rejmánek M (1996) A theory of seed plant invasiveness: the first sketch. Biol Conserv 78:171-181

Rejmánek M (2000) Invasive plants: approaches and predictions. Austral Ecol 25:497506

Rejmánek M, Richardson DM (1996) What attributes make some plant species more invasive? Ecology 77:1655-1661

Rejmánek M, Richardson DM, Higgins SI, Pitcairn MJ, Grotkopp E (2005) Ecology of invasive plants: state of the art. In: Mooney HA, Mack RM, McNeely JA, Neville L, Schei P, Waage J (eds) Invasive alien species: searching for solutions. Island Press, Washington, DC, pp 104-161

Richardson DM, Bond WJ (1991) Determinants of plant-distribution - evidence from pine invasions. Am Nat 137:639-668

Richardson DM, Cowling RM (1992) Why is mountain fynbos invasible and which species invade? In: Van Wilgen BW, Richardson DM, Kruger FJ, van Hensbergen HJ (eds) Fire in South African mountain fynbos. Springer, Berlin Heidelberg New York, pp 161-181

Richardson DM, Pyšek P (2006) Plant invasions: merging the concepts of species invasiveness and community invasibility. Prog Phys Geogr 30:409-431

Richardson DM, Rejmánek M (2004) Conifers as invasive aliens: a global survey and predictive framework. Diversity Distrib 10:321-331

Richardson DM, Pyšek P, Rejmánek M, Barbour MG, Panetta FD, West CJ (2000a) Naturalization and invasion of alien plants: concepts and definitions. Diversity Distrib 6:93-107

Richardson DM, Allsopp N, D’Antonio CM, Milton SJ, Rejmánek M (2000b) Plant invasions: the role of mutualisms. Biol Rev 75:65-93

Roy J (1990) In search of characteristics of plant invaders. In: di Castri J, Hansen AJ, Debussche M (eds) Biological invasions in Europe and the Mediterranean Basin. Kluwer, Dordrecht, pp 335-352

Schierenbeck K, Mack RN, Sharitz RR (1994) Effects of herbivory on growth and biomass allocation in native and introduced species of Lonicera. Ecology 75:1661-1672

Smith MD, Knapp AK (2001) Physiological and morphological traits of exotic, invasive exotic, and native plant species in tallgrass prairie. Int J Plant Sci 162:785-792 
Sutherland S (2004) What makes a weed a weed: life history traits of native and exotic plants in the USA. Oecologia 141:24-39

Thébaud C, Simberloff D (2001) Are plants really larger in their introduced ranges? Am Nat 157:231-236

Thompson K (1994) Predicting the fate of temperate species in response to human disturbance and global change. In: Boyle TJB, Boyle CEB (eds) Biodiversity, temperate ecosystems and global change. Springer, Berlin Heidelberg New York, pp 61-76

Thompson K, Band SR, Hodgson JG (1993) Seed size and shape predict persistence in soil. Funct Ecol 7:236-241

Thompson K, Hodgson JG, Rich TCG (1995) Native and alien invasive plants: more of the same? Ecography 18:390-402

Timmins SM, Williams PA (1987) Characteristics of problem weeds in New Zealand's protected natural areas. In: Saunders DA, Arnold G, Burbidge A, Hopkins A (eds) Nature conservation: the role of remnants of native vegetation. Surrey Beatty, Chipping Norton, pp 241-247

Williamson M (1993) Invaders, weeds and the risk from genetically manipulated organisms. Experientia 49:219-224

Williamson MH, Fitter A (1996) The characters of successful invaders. Biol Conserv 78:163-170 
